\title{
Electrochemical behavior of hybrid carbon nano materials: the chemistry behind electrochemistry
}

María Moreno-Guzman, ${ }^{\mathrm{a}}$ Aída Martín, ${ }^{\mathrm{a}}$ María del Carmen Marín, ${ }^{\mathrm{a}}$ Tania Sierra, Alejandro Ansón-Casaos, ${ }^{\mathrm{b}}$ María Teresa Martínez ${ }^{\mathrm{b}^{*}}$ and Alberto Escarpa ${ }^{\mathrm{a}^{*}}$

a Department of Analytical Chemistry, Physical Chemistry and Chemical Engineering, University of Alcala, E-28871, Alcalá de Henares, Spain

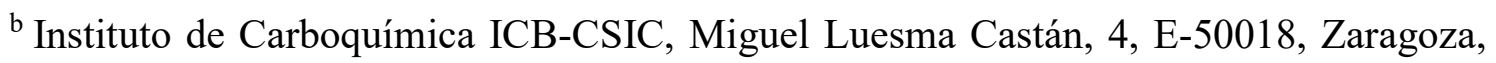
Spain.

*Corresponding authors: alberto.escarpa@uah.es, mtmartinez@icb.csic.es

\begin{abstract}
The unzipping of temperature-induced multi-walled carbon nanotubes (MWCNTs) to yield graphene nanoribbons (GNRs) has been studied. These carbon nanomaterials consisting of MWCNTs and unzipped MWCNTs have been synthesized, thoroughly characterized, and subsequently evaluated for electrochemical sensing. Three temperatures $\left(55,65\right.$ and $\left.75^{\circ} \mathrm{C}\right)$ yielding three carbon nanomaterial termed as GNR-55, GNR-65 and GNR-75, respectively, were carefully studied. Interestingly, GNR-65 became the most suitable material for the electrochemical sensing of a wide range of model analytes displaying the best electrochemical response with independence of the analysed molecule. This electrochemical behaviour seems to be associated to the progress of the unzipping reaction that influences the balance between the $\mathrm{Csp}^{2} / \mathrm{Csp}^{3}$ ratio, the graphitic fraction and the type of functional groups introduced. These results revealed the importance of the temperature in the synthesis process, for tailoring carbon nanomaterials which could be used in a particular molecular detection application opening new opportunities for electrochemical sensing applications.
\end{abstract}




\section{Introduction}

An exciting set of emerging nanomaterials with unusual nanoscopic structure-dependent properties has been largely developed over the last decades. Among them, lowdimensional carbon allotropes, are the most widely investigated nanomaterials presenting promising applications in different fields [1-4]. Carbon materials offer a tremendous versatility, providing tailored electrochemistry for target applications [5]. This versatility is based on the selection of a target carbon nanomaterial, controlling its synthesis, functionalization and the chemistry behind its electrochemical behaviour, [6-8] which is going to determine the final electrochemical performance. Two relevant examples of carbon nanomaterials are carbon nanotubes (CNTs) and graphene oxide nanoribbons (GONRs). CNTs are nanomaterials with excellent geometrical, mechanical, electronic and chemical properties, which offer favourable features derived from the associated electron transfer enhancement and their strong adsorption capacity [9,10]. Graphene, on the other hand, is an atomically thin sheet of $\mathrm{sp}^{2}$ bonded carbon atoms forming a twodimensional (2-D) honeycomb lattice. This structure provides, this material, its extraordinary properties such as high surface area, theoretically $2630 \mathrm{~m}^{2} / \mathrm{g}$ for singlelayer,[11] and double than single-walled CNTs and high electrical and thermal conductivities, among others [12,13]. The chemically modified graphene materials employed for analytical electrochemistry include either graphene oxide or reduced graphene oxide when the carbon source is graphite, and GONRs when carbon nanotubes are unzipped [14-16].

GONRs are unzipped multi-walled carbon nanotubes (MWCNTs). Among the different routes used for synthesizing GONRs [17,18], the chemical oxidation of the CNTs [17] has been highly used in electrochemistry generating functionalities and defects in the GONRs. [8] GONRs present the inherent properties of graphene such as high surface area and high electrical conductivity plus the extreme reactivity due to the existence of defects in the open-ended graphene sheets [19-21].

The synergistic effects of the MWCNT and the GONR result in an improved electrochemistry, as shown in the detection of ascorbic acid, uric acid and dopamine [22], p-dihydroxybenzene [23], polycyclic aromatic amines [24] or in biosensing [25]. However, the roadblock in the preparation of these materials is the control of the reaction conditions. The oxidation of carbon materials is extremely difficult to control. While the 
temperature has to be high enough to promote the unzipping of the MWCNTs, the overoxidation has to be avoided. The balance between temperature and oxidation time seems to be critical to obtain electrochemically active hybrid nanomaterials [21].

In a previous work, we have reported the influence of the reaction time on the MWCNT unzipping at a fix temperature [21]. The reported results indicated that the reaction time had a huge influence in the oxidation, unzipping degree, structural characteristics and electrochemical behaviour. In that study, the sample obtained at $55^{\circ} \mathrm{C}$ and the lowest reaction time showed the highest heterogeneous charge transfer constant and sensitivity towards $\mathrm{H}_{2} \mathrm{O}_{2}$ oxidation of all samples, as well as better electrochemical performance than the chemically and electrochemically reduced samples. The necessity of the carbon and electrochemistry communities to look for tailored nanomaterial for specific electrochemical applications, make us explore the temperature influence surrounding $55^{\circ} \mathrm{C}$, the temperature previously used, and establish the particular structural characteristics that render this hybrid material more electrochemically active.

Herein, we have explored the inherent possibilities offered by the chemical synthesis of the GONRs from the opening of MWCNTs. Our hypothesis is that, by controlling the chemistry involved in the synthesis process, we could improve its electrochemical performance and suggest advanced materials for electrochemical sensing. Thus, we propose new tools for electrochemical sensing, over the control of the opening and oxidation of MWCNTs at different temperatures. 


\section{Experimental part}

\subsection{Reagents and standards}

Sodium dihydrogen phosphate (141965) and disodium hydrogen phosphate (141679) to prepare a phosphate buffered solution (PBS), and potassium hexacyanoferrate (III) (131503) were purchased from Panreac (Badalona, Spain). Potassium chloride (PO01991000) was purchased from Scharlau (Barcelona, Spain). Potassium hexacyanoferrate (II) (P3289), hexaammineruthenium (III) chloride (262005) and hexaammineruthenium (II) chloride (303690) were purchased from Sigma Aldrich (St. Louis, MO, USA).

Dopamine (DP) (H60255), uric acid (UA) (U2625), catechol (CT) (C9510), resorcinol (RS) (307521), hydroxytyrosol (HT) (H4291), L-tyrosine (TYR) (93829) and MWCNTs (406074) were purchased from Sigma Aldrich (St. Louis, MO, USA) and tyrosol (TYL) (79058) from Fluka Chemika (Buchs, UK).

All standards solutions were daily prepared in $0.05 \mathrm{mM}$ PBS pH 7.40 with ultrapure water (Millipore, Bedford, MA, USA), and protected from light.

\subsection{Apparatus and measurements}

All electrochemical and impedance measurements were performed, at room temperature, on an electrochemical station PGSTAT-204 (Autolab, Utrecht, Holland) using a conventional three-electrode system comprising of a platinum wire as an auxiliary electrode, a silver/silver chloride $(\mathrm{Ag} / \mathrm{AgCl}), 3 \mathrm{M} \mathrm{KCl}$ as a reference electrode $(\mathrm{CH}$ Instrument, China), and a glassy carbon electrode (GCE) $3.0 \mathrm{~mm}$ in diameter (BAS Instrumental, Warwickshire, UK) as the working electrode.

Elemental analysis was performed in a ThermoFlash1112 analyzer. For the determination of carbon, hydrogen, nitrogen, and sulfur, the sample was treated at $950{ }^{\circ} \mathrm{C}$ in an $\mathrm{O}_{2}$ flow and in the presence of $\mathrm{V}_{2} \mathrm{O}_{5}$. The combustion gas products pass through a $\mathrm{CuO}$ oxidant bed at $950{ }^{\circ} \mathrm{C}$, which transforms them in to $\mathrm{NO}_{\mathrm{x}}, \mathrm{CO}_{2}, \mathrm{H}_{2} \mathrm{O}$, and $\mathrm{SO}_{2}$. Subsequently, the gases pass through a copper reducing bed at $500{ }^{\circ} \mathrm{C}$, which converts $\mathrm{NO}_{\mathrm{x}}$ into $\mathrm{N}_{2}$. The resulting gases were separated in a polar chromatographic column, and quantified by gas chromatography using a thermal conductivity detector calibrated with sulfanilamide. For the direct oxygen determination, the pyrolysis of the materials was carried out at 1080 
${ }^{\circ} \mathrm{C}$. The evolved carbon gases were reduced to $\mathrm{CO}$ in a carbon black bed, water moisture was trapped in $\mathrm{Mg}\left(\mathrm{ClO}_{4}\right)_{2}$, and the other pyrolysis gases were separated in a polar chromatographic column.

X-ray diffraction (XRD) was carried out in a Bruker AXS D8 Advance diffractometer

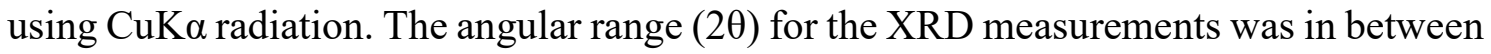
3 to $40^{\circ}$, step size $0.05^{\circ}$ and time/step 5 s. Fourier Transform Infrared spectroscopy (FTIR) measurements were carried out in a Bruker Vertex 70 spectrometer. The samples were prepared by mixing small amounts of the powder samples with spectroscopic-grade $\mathrm{KBr}$ and pressing to form pellets. X-ray photoelectron spectroscopy (XPS), was performed in an ESCAPlus Omicron spectrometer provided with a $\mathrm{Mg}$ anode $(1253.6 \mathrm{eV})$ working at $150 \mathrm{~W}(15 \mathrm{~mA}, 10 \mathrm{kV})$, CASA software was used for the peak deconvolution. Thermogravimetric analysis (TGA) were carried out in a model Q600 from TA Instruments.

Micro-Raman spectroscopy was performed in a HORIBA Jobin Yvon spectrometer (model HR $800 \mathrm{UV}$ ) working with a green laser at $532 \mathrm{~nm}$. Raman measurements were carried out with a filter 06 leading to $0.6 \mathrm{~mW}$ of power, hole side 500 and 1800 grating. For each material, 5-6 representative spectra of different sample zones were considered. Raman frequencies were calibrated with the Si line at $520 \mathrm{~cm}^{-1}$ and with the peak of highly oriented pyrolytic graphite at $1582 \mathrm{~cm}^{-1}$. The estimated accuracy was $1 \mathrm{~cm}^{-1}$, and the spectral resolution was better than $3 \mathrm{~cm}^{-1}$. The Raman spectra presented correspond to the raw data with only the base line correction with LabSpec 5 software.

Transmission electron microscopy was performed in JEOL-200FXII equipment using $\mathrm{C} / \mathrm{Cu} 200$ mesh Lacey microscopy grids. Specific surface areas were calculated by the Brunauer-Emmett-Teller (BET) method from the nitrogen adsorption isotherms and for the hydrogen adsorption isotherms from the monolayer capacity using the diameter of the hydrogen molecule. Samples were out-gassed at $150^{\circ} \mathrm{C}$ and $3 \times 10^{-3} \mathrm{~mm} \mathrm{Hg}$. Nitrogen and hydrogen isotherms were measured at the liquid nitrogen temperature in a Micromeritics ASAP 2020 equipment.

\subsection{Synthesis of carbon hybrid nanomaterials}

Carbon hybrid nanomaterials consisting of MWCNTs and GONRs were synthesized by unzipping commercially available MWCNTs (Aldrich 406074) using a slightly modified 
Tour method.[17,26] MWCNTs length is in the range of 0.5 to $10 \mu \mathrm{m}$ with outer diameters between 7 to $12 \mathrm{~nm}$. In a typical experiment, $150 \mathrm{mg}$ of arc-discharge MWCNTs were dispersed by ultrasonication in $150 \mathrm{~mL}$ of concentrated $\mathrm{H}_{2} \mathrm{SO}_{4}$. Afterwards, the dispersion was heated up to the target temperature and $750 \mathrm{mg}$ of $\mathrm{KMnO}_{4}$ were added. After 15 minutes, the dispersion of the hybrid material containing MWCNTs and GONRs was poured onto $400 \mathrm{~g}$ of ice and $10 \mathrm{~mL}$ of $\mathrm{H}_{2} \mathrm{O}_{2}$ solution was added. Three different temperatures $55^{\circ} \mathrm{C}, 65^{\circ} \mathrm{C}$ and $75^{\circ} \mathrm{C}$ were tested. The reaction product was vacuum-filtered through a $3.0 \mu \mathrm{m}$ polycarbonate membrane, dispersed in $150 \mathrm{~mL}$ of ultrapure water, flocculated with $\mathrm{HCl}$, filtered through a $3.0 \mu \mathrm{m}$ polycarbonate membrane, redispersed in $150 \mathrm{~mL}$ of ethanol, flocculated with $150 \mathrm{~mL}$ ether $+15 \mathrm{~mL}$ hexane and filtered through a $10.0 \mu \mathrm{m}$ PTFE membrane. Finally, it was dried at $60^{\circ} \mathrm{C}$ in a vacuum oven for $24 \mathrm{~h}$.

\subsection{Preparation of the GONR-based electrodes}

MWCNTs and GONRs samples $(0.50 \mathrm{mg} / \mathrm{mL}$ were dispersed in water (except MWCNTs in water- $\mathrm{NH}_{3} 3 \% \mathrm{v} / \mathrm{v}$ ) by bath ultrasonication during $30 \mathrm{~min}$ followed by tip sonication using a VCX130 (Sonics, Newtown, USA) for 4 min at 50\% amplitude.

Prior to drop-casting deposition, the GCE were in turn polished using 0.1 and $0.05 \mu \mathrm{m}$ alumina powders and sequentially sonicated in ultrapure water and anhydrous ethanol. The MWCNT and GONR-modified electrodes were prepared by casting of previously optimized volume of $5.00 \mu \mathrm{L}$ on the GCE surface from the GONRs or MWCNTs dispersions allowing drying and solvent evaporation. The volume deposited was optimized and some of the results are detailed Figure S5.

\subsection{Electrochemical characterization of the GONR-based electrodes}

Electrochemical characterization by cyclic voltammetry (CV) was carried out using 5 $\mathrm{mM} \mathrm{Fe}(\mathrm{CN})_{6}{ }^{4-/ 3-}$ and $\mathrm{Ru}\left(\mathrm{NH}_{3}\right)_{6}{ }^{2+/ 3+}$ in $0.1 \mathrm{M} \mathrm{KCl}$ and $0.01 \mathrm{M}$ PBS. CV voltammograms were recorded from $-0.60 \mathrm{~V}$ to $+0.80 \mathrm{~V}$ at scan rate of $50 \mathrm{mV} / \mathrm{s}$. Electrochemical characterization of GONR-based electrodes by Electrochemical Impedance Spectroscopy (EIS) was carried out using $5 \mathrm{mM} \mathrm{Fe}(\mathrm{CN})_{6}{ }^{4-/ 3-}$ and $\mathrm{Ru}\left(\mathrm{NH}_{3}\right)_{6}{ }^{2+/ 3+}$ in $0.1 \mathrm{M} \mathrm{KCl}$ and starting at open circuit potential (OCP) using ac signals of amplitude $5 \mathrm{mV}$ peak to peak in the frequency range of $10^{9} \mathrm{~Hz}$ to $10^{4} \mathrm{~Hz}$. Differential pulse voltammetry (DPV) was 
used for the electrochemical sensing of the target molecules with a pulse amplitude of 70 $\mathrm{mV}$, a pulse width $0.05 \mathrm{~s}$, a standing time of $2 \mathrm{~s}$ and at scan rate of $5 \mathrm{mV} / \mathrm{s}$.

\section{Results and discussion}

\subsection{Synthesis of carbon hybrid nanomaterials}

The carbon hybrid nanomaterials were synthesized from MWCNTs. Table 1 lists the carbon nanomaterial terminology, the oxidation temperature conditions for yielding each of the materials, the oxygen and carbon content from the element analysis and the weight loss from thermogravimetric analysis (TGA) (see further TGA data in Figure S1 from room temperature to $900^{\circ} \mathrm{C}$ of the carbon nanomaterials studied).

MWCNTs as synthetic source and the produced GONRs termed as GONR-55, GONR65 and GONR-75 subjected to the same oxidation time of 15 minutes at different temperatures of $55^{\circ} \mathrm{C}, 65^{\circ} \mathrm{C}$ and $75^{\circ} \mathrm{C}$, respectively, were carefully studied.

Table 1. Material terminology, oxidation temperature, carbon and oxygen elemental analysis and weigh loss from thermogravimetric analysis (TGA) for MWCNTs and GONRs.

\begin{tabular}{cccccc}
\hline Material & $\mathbf{T}\left({ }^{\circ} \mathbf{C}\right)$ & $\% \mathbf{O}$ & $\% \mathbf{C}$ & $\mathbf{C} / \mathbf{O}$ & Total weight loss $<\mathbf{9 0 0}^{\circ} \mathbf{C}$ \\
\hline MWCNTs & --- & 0.100 & 99.85 & --- & 0.20 \\
\hline GONR-55 & 55 & 25.61 & 65.68 & 3.42 & 33.58 \\
\hline GONR-65 & 65 & 30.50 & 61.28 & 2.68 & 40.45 \\
\hline GONR-75 & 75 & 35.09 & 57.85 & 2.20 & 51.07 \\
\hline
\end{tabular}

The oxygen content steeply increases upon oxidation during de unzipping process likewise, $\mathrm{C} / \mathrm{O}$ atomic ratio gradually decreases and the weight loss until $900^{\circ} \mathrm{C}$ increases as the amount of functional groups as the oxidation progresses. MWCNTs weight loss is only $0.20 \mathrm{wt} . \%$ that agrees with the low oxygen and functional groups content. TGA profiles for GONR samples (Figure S1) are similar showing a sharp weight loss decrease until $200^{\circ} \mathrm{C}$, a change in the slope between 200 and $300^{\circ} \mathrm{C}$ that is more abrupt for GONR75 sample and finally a gradual weight loss from 400 to $800^{\circ} \mathrm{C}$. Besides, $t$ The calculation of the Brunauer-Emmett-Teller (BET) surface area indicates also-suggests-a slightly increment with the oxidation from $18.3 \mathrm{~m}^{2} / \mathrm{g}$ for the starting MWCNTs to 42.4, 
45.0 to $44.2 \mathrm{~m}^{2} / \mathrm{g}$ for GONR-55, GONR-65 and GONR-75, respectively. As expected, due to the smaller size of hydrogen molecule, the physical area determined by performing hydrogen adsorption isotherms gave higher values than those obtained from nitrogen isotherms; $19 \mathrm{~m}^{2} / \mathrm{g}$ for the starting MWCNTs, and 85, 110 and $76 \mathrm{~m}^{2} / \mathrm{g}$ for GONR-55, GONR-65 and GONR-75, respectively. Hydrogen adsorption isotherms were fitted to the so-called unilan equation, which was developed by Honig and Reyerson [27]. The model is based on an uniform distribution of adsorption energies and the specific surface area can be directly calculated from the monolayer capacity knowing the diameter of the adsorbed molecule. The hydrogen hard sphere diameter $(257 \mathrm{pm})$ is assumed for the calculation of specific surface areas. Sample GONR-65 showed the highest physical area for both hydrogen and nitrogen adsorption isotherms.

\subsection{Structural characterization of GONRs}

The synthesized carbon nanomaterials were fully characterized by different techniques such as XRD, Raman, FTIR, XPS and TEM to establish differences according to the different processing temperatures.

Figure 1A depicts the XRD diffractograms of MWCNTs and GONRs materials. MWCNTs profile only shows one diffraction peak at $2 \theta \sim 26^{\circ}$ corresponding to highly crystallized graphite. As the unzipping process progress a second XRD peak corresponding to a few layer graphene oxide is visible at $2 \theta \sim 10^{\circ}$. This peak became more prominent by increasing the temperature processing. We have estimated the unzipped fraction of MWCNTs as the graphitic fraction by calculating the ratio between the area of the peak at $2 \theta \sim 26^{\circ}$ and the addition of the peaks at around $10^{\circ}$ and $26^{\circ}$ [21]. This graphitic fraction, correspondent to the quantity of unzipped MWCNTs, is 1 for MWCNTs and 0.64, 0.25 and 0.15 for GONR55, GONR65 and GONR75 materials respectively indicating both the progress of the unzipping process upon oxidation and the hybrid composition in both MWCNTs and GONRs in all assayed materials. 

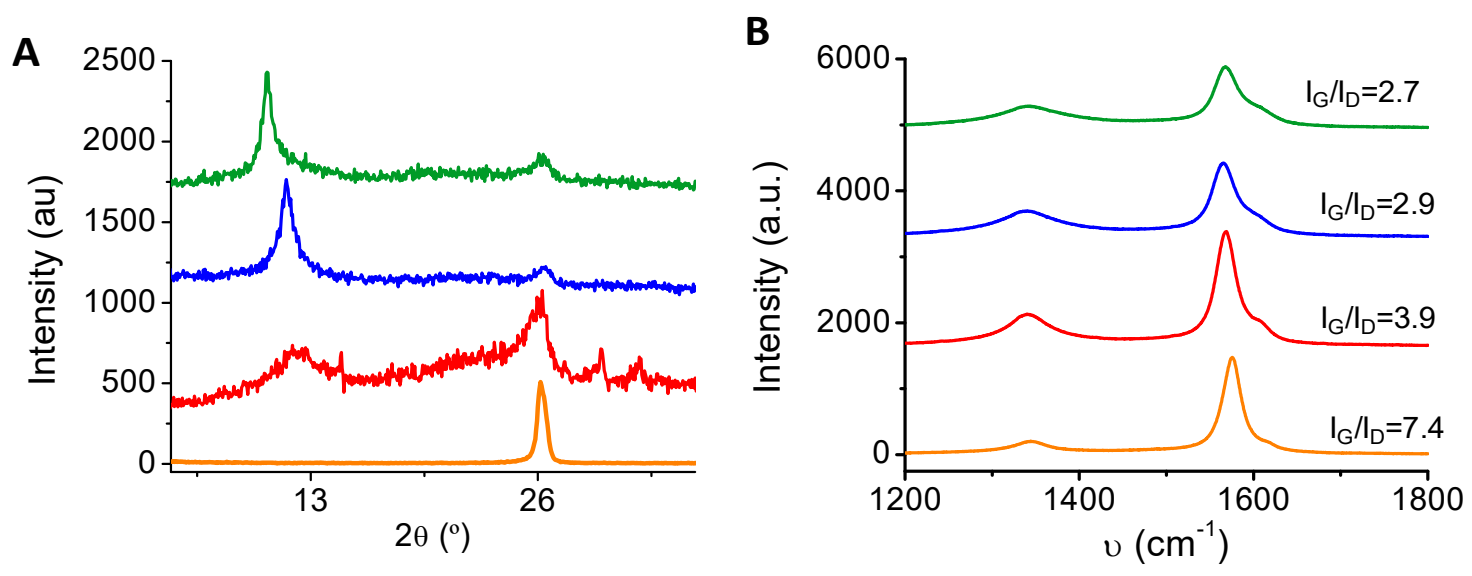

Figure 1. (A) XRD diffractograms and (B) Raman spectra (532 nm) of MWCNTs, GONR-55, GONR-65 and GONR-75 materials

Figure 1B shows the Raman spectra of pristine and unzipped MWCNTs. These spectra show the two characteristic bands of the graphitic-based materials; the G-band that appears from the $\mathrm{sp}^{2}$-hybridized carbon vibrations mode at about $1565 \mathrm{~cm}^{-1}$, and the Dband at about $1340 \mathrm{~cm}^{-1}$ due to structural disorder and $\mathrm{sp}^{3}$-like defects in $\mathrm{sp}^{2}$-conjugated carbon atoms. The changes in the intensities ratio of the D-band and G-band have been associated to defects and disorders in the graphitic-based materials [28, 29]. Thus, the $\mathrm{I}_{\mathrm{G}} / \mathrm{I}_{\mathrm{D}}$ ratio was the highest for pristine MWCNTs and decreased with the oxidation of the materials. While there was an important decrease in $\mathrm{I}_{\mathrm{G}} / \mathrm{I}_{\mathrm{D}}$ intensity ratio in the MWCNTs material after the unzipping at $55^{\circ} \mathrm{C}$ and $65^{\circ} \mathrm{C}$, the reduction was lower between $65^{\circ} \mathrm{C}$ and $75^{\circ} \mathrm{C}$.

To obtain further information about the oxygenated functional groups introduced in the oxidative treatment, FTIR characterization was carried out (see Figure S2). The raw MWCNTs spectrum presented a band at $3437 \mathrm{~cm}^{-1}$ usually associated to O-H stretching mode hydroxyl and very weak bands at 1634, 1580, 1384 and $1045 \mathrm{~cm}^{-1}$. The band at $\approx$ $1600 \mathrm{~cm}^{-1}$ reflected the skeletal vibration of $\mathrm{C}=\mathrm{C}$ aromatic stretching of aromatic rings [30] and the others bands at $\approx 1580 \mathrm{~cm}^{-1}$ and in the region of $1000-1300 \mathrm{~cm}^{-1}$, were due to various oxygenated functional groups. As the oxidation progressed and the oxygen content increased, see Table S1, the materials became more hydrophilic, particularly materials oxidized at 65 and $75^{\circ} \mathrm{C}$, increasing the water content and the bands intensity at $\approx 3400 \mathrm{~cm}^{-1}$ and at $\approx 1620 \mathrm{~cm}^{-1}$, this last one assigned to $\mathrm{O}-\mathrm{H}$ of adsorbed water molecules, particularly in materials oxidized at 65 and $75^{\circ} \mathrm{C}$. Likewise, a new band at $1723 \mathrm{~cm}^{-1}$ 
( $\mathrm{C}=\mathrm{O}$ stretching vibration) corresponding to lactone and carboxylic groups was visible in oxidized materials together with the carboxylate band at $1585 \mathrm{~cm}^{-1}$. The wide bands centred at $1385 \mathrm{~cm}^{-1}$ corresponded to $\mathrm{O}-\mathrm{H}$ stretching of phenols or tertiary alcohols [31]. All the materials also showed the band at $1220 \mathrm{~cm}^{-1}$ assigned to the $\mathrm{C}-\mathrm{O}$ stretch of phenol groups [32] and the band at $1050 \mathrm{~cm}^{-1}$ corresponding to C-O stretch of primary alcohols. Furthermore, the C-O- bands at $\approx 1250$ and at $890-800 \mathrm{~cm}^{-1}$ could be assigned to the bending and stretching vibrations of epoxy and oxirane rings [32] were more evident in the material oxidized at $75^{\circ} \mathrm{C}$. Overall, GONR-65 and GONR-75 FTIR spectra were similar showing the same band profile with different intensity. However, GONR-55 material showed an extra band at $1180 \mathrm{~cm}^{-1}$ assigned to $\mathrm{C}-\mathrm{O}$ stretch of secondary alcohols, which was not present in the materials obtained at higher temperatures, probably due to the oxidation of alcohols to ketones and carboxylic acids with the progress of the oxidation.

To further elucidate the main oxygen functionalities of the materials, C1s and O1s X-ray photoelectron spectroscopy (XPS) characterization was also performed (see Figure S3 and Table 2). The C1s XPS spectrum of MWCNTs shows a main peak centered at 284.2 $\mathrm{eV}$ assigned to $\mathrm{sp}^{2}$ graphitic carbon that has been fitted with the Doniach Sunjic lineshape to an asymmetric peak shape typical of conductive graphite [33] and other contribution at $291.6 \mathrm{eV}$ due to plasmon loss. The partially unzipped MWCNT at 55, 65 and $75^{\circ} \mathrm{C}$ show the most dominant peak in $\mathrm{C} 1 \mathrm{~s}$ spectra at $\sim 284.5 \mathrm{eV}$ assigned to $\mathrm{C}-\mathrm{C}$ bonds. This band consists of two components at $\sim 284.3 \mathrm{eV}$ and $\sim 285 \mathrm{eV}$ due to $\mathrm{sp}^{2}$ graphitic carbon and $\mathrm{Csp}^{3}$, respectively. The other band at higher binding energy, corresponding to oxygen functionalities, has been deconvoluted in three components; i) alcohols/phenols at $286.3 \pm 0.3 \mathrm{eV}$, ii) keto groups at $287.6 \pm 0.3$ and iii) $(\mathrm{H}) \mathrm{O}-\mathrm{C}=\mathrm{O}$ carboxyl at $289.1 \pm 0.3 \mathrm{eV}$ and a small contribution at $291.3 \pm 0.3$ due to plasmon loss.

The amount of $\mathrm{Csp}^{2}$ decreases with the oxidation degree that is in agreement with the decrease of the Raman $I_{G} / I_{D}$ ratio and with the increase of oxygen content, progressively anchored to the aromatic $\mathrm{Csp}^{2}$ network. On the contrary, the total $\mathrm{Csp}^{3}$ and the $\mathrm{C}-\mathrm{O}$ contributions increase with the oxidation degree. Important observation is the low intensity of the $\mathrm{COOH}$ contribution at $\sim 289 \mathrm{eV}$ for the oxidized samples indicating that overoxidation has been avoided, probably as a consequence of the short reaction time. It is worth noting that the C1s XPS spectrum of GONR-65 material shows the maximum 
contribution of alcohols and phenols and the minimum contribution of the more oxidized keto groups.

XPS O1s spectra of carbon materials are typically deconvoluted in several sub-bands [30]. Table 2 includes the oxygen group binding energies and area percentages of deconvoluted XPS spectra. The O1s XPS spectra confirm the low presence of carboxylic groups observed in C1s XPS. Remarkably, the highest contribution of alcohol and phenols in sample GONR65 shown in C1s spectra was confirmed by the highest contribution at $\sim 532.3 \mathrm{eV}$ corresponding to hydroxyls and $\mathrm{C}-\mathrm{O}$ in ester and anhydrides.

Table 2. XPS data for $\mathrm{C} 1 \mathrm{~s}$ and $\mathrm{O} 1 \mathrm{~s}$ : binding energies in $\mathrm{eV}$ and area percentages (in parenthesis).

\begin{tabular}{ccccccc}
\hline \multicolumn{7}{c}{ XPS C1s } \\
\hline Material & graphitic sp & \multirow{2}{*}{ Csp $^{\mathbf{3}}$} & Alcohols/phenols & Keto groups & $\begin{array}{c}\text { (H)O-C=O } \\
\text { carboxyl }\end{array}$ & Plasmon loss \\
\hline MWCNTs & $284.2(97.2)$ & & & & --- & $290.6(2.8)$ \\
\hline GONR-55 & $284.5(48.3)$ & $285.1(14.3)$ & $286.4(17.8)$ & $287.1(13.0)$ & $288.8(4.6)$ & $290(2)$ \\
\hline GONR-65 & $284.5(40.9)$ & $285.1(15.5)$ & $286.7(31.6)$ & $287.8(6.5)$ & $288.8(4.0)$ & $290.7(1.5)$ \\
\hline GONR-75 & $284.1(35.0)$ & $285.0(20.2)$ & $286.5(28.0)$ & $287.9(9.7)$ & $288.8(5.3)$ & $290.0(1.6)$ \\
\hline
\end{tabular}

\begin{tabular}{ccccc}
\hline Material & C=O carbonyl & $\begin{array}{c}\text { Hydroxyls, ethers and C=O in } \\
\text { esters, and anhydrides }\end{array}$ & $\begin{array}{c}\text { C-O esters and } \\
\text { anhydrides }\end{array}$ & Carboxylic groups \\
\hline MWCNTs & $531.5(47.9)$ & & $533.2(52.1)$ & \\
\hline GONR-55 & $531.4(12.3)$ & $532.2(19.7)$ & $532.9(64.8)$ & $535.2(3.2)$ \\
\hline GONR-65 & $531.4(5.5)$ & $532.3(37.9)$ & $532.9(53.8)$ & $535.3(2.8)$ \\
\hline GONR-75 & $531.2(7.4)$ & $532.1(22.5)$ & $532.8(63.1)$ & $534.4(6.9)$ \\
\hline
\end{tabular}

Figure 2 shows TEM micrographs of the GONR materials, which confirm the presence of hybrid materials composed of unzipped MWCNTs and GONRs. GONRs show the presence of MWCNTs and thin layers of exfoliated ribbons transparent to the electrons fully opened with wrinkles and folded edges. There were also GONRs sheets stacked together due to strong interlayer van der Waals interactions. MWCNTs show internal diameter around 4-5 $\mathrm{nm}$ and external of 10-16 $\mathrm{nm}$ and Figure 2B and 2D show sheets of about $150 \mathrm{~nm}$ and more than $1 \mu \mathrm{m}$ wide respectively that points out to the presence of scrolled MWCNTs as it has been reported by Wong and Pumera [34]. 

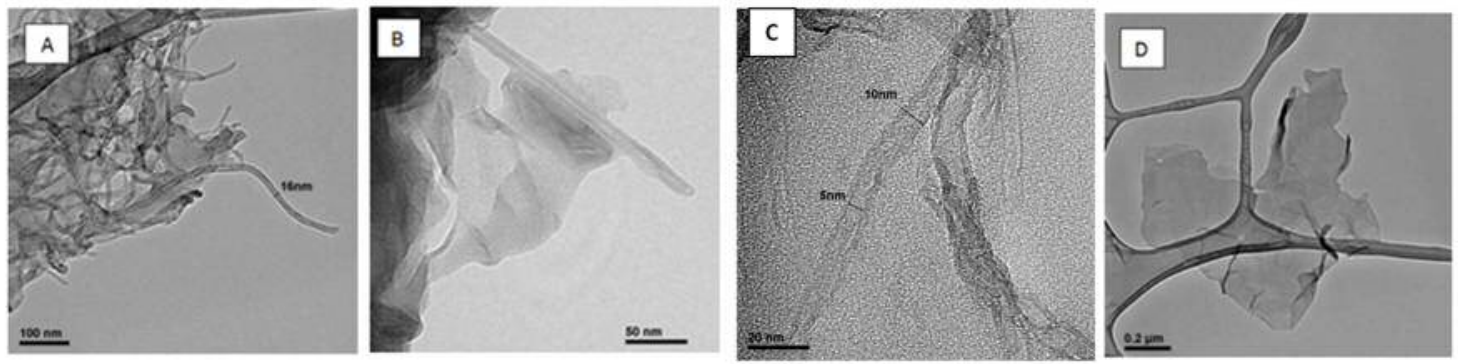

Figure 2. TEM images of (A) MWCNTs (scale bar $100 \mathrm{~nm}$ ) and GONRs materials: (B) GONR-55 (scale bar $50 \mathrm{~nm}$ ), (C) GONR-65 (scale bar $20 \mathrm{~nm}$ ) and (D) GONR-75 (scale bar $0.2 \mu \mathrm{m})$.

\subsection{Electrochemical characterization of GONRs}

Afterwards, the carbon nanomaterials were characterized by using electrochemical techniques. Prior to characterize all the modified surfaces, Fable S2 illustrates the optimization study of the volume casted on the GCE showing the variation with the quantity of material, in terms of volume of dispersion drop-casted on the GCE, peak current ratio and peak potential separation redox differential potential for the studied $\mathrm{Fe}(\mathrm{CN}) 6^{3-/ 4-}$ redox system were evaluated. This redox probe allows modifications in the electrochemical behavior with small variations in the material content [35]. Figure 3(AB) shows cyclic voltammograms $(\mathrm{CV})$ of $\mathrm{Fe}(\mathrm{CN})_{6}{ }^{4-3-}$ and $\mathrm{Ru}\left(\mathrm{NH}_{3}\right)_{6}{ }^{2+/ 3+}$ redox probes for each nanomaterials assayed, GONRs, MWCNTs and the bare glassy carbon electrode (GCE) using 0.1 M KCl. All the GONRs, MWCNT and bare GCE surfaces showed MWCNT showed a smaller intensity currents and higher peak potential separation redox differential potential, the GONRs and the bare GCE showedsimilar intensity currents and close anodic and cathodic redox potentials in both redox couples been more similar in $\mathrm{Ru}\left(\mathrm{NH}_{3}\right)_{6}{ }^{2+/ 3+}$ for being this a outer sphere redox probe.[35] Consequently, we performed the CVs in 0.01 M PBS. At these conditions, see Figure S4(A-B) and Table S3, the differences in peak current ratio and peak potential separation redox differential potentials were more accentuated than with $0.1 \mathrm{M} \mathrm{KCl}$. MWCNT displayed the lowest peak current ratio and the highest peak potential separation redox differential potential, GONR 65 showed the best reversibility performance with a peak current ratio, close to 1 and $\Delta \mathrm{E}=188 \mathrm{mV}$ in comparison with GCE. These differences in between the materials were not extremely high. 
On the other hand, electrochemical impedance spectroscopy (EIS) is a useful technique to investigate the surface characteristics of the modified electrodes. Figure 3(C-D) shows the EIS results for the three target nanomaterials (GONR-55, GONR-65, GONR-75) and MWCNTs and GCE as controls using $\mathrm{Fe}(\mathrm{CN})_{6}{ }^{4-/ 3-}$ and $\mathrm{Ru}\left(\mathrm{NH}_{3}\right)_{6}{ }^{2+/ 3+}$ as electroactive

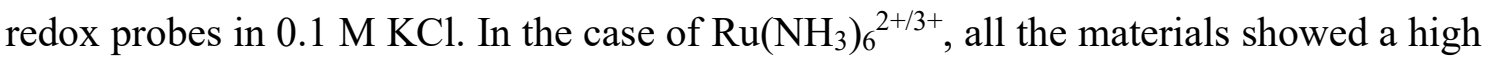
conductive behavior indicated by showing a linear tendency indicating diffusive control in all cases. As for $\mathrm{Fe}(\mathrm{CN})_{6}^{4-/ 3-}$, GONRs and GCE did not show big differences, only MWCNTs showed an important influence on the resistance to charge transfer (Rct) of the modified electrode $(\operatorname{Rct}(\Omega)=112.61,150.0,84.4,80.0$ and 101.3; for GCE, MWCNT, GONR-55, GONR-65, and GONR-75; respectively, see Table S2). It was reflected in the diameter of the semicircle in Nyquist plot in lower frequency region and a linear zone in the region of higher frequencies, indicating a diffusive control throughout the frequency range studied. Lower diameters imply lower Ret and the better electrical conductivity of the electrodic surface. However, the use of $0.01 \mathrm{M} \mathrm{PBS}$, due to the lower ionic strength, allow finding differences in between the materials studied, see Figure S4(C-D) and Table S2. The higher Rct in the EIS experiments for $\mathrm{Fe}(\mathrm{CN})_{6}{ }^{4-3}$ could be associated to the more resistant character of the nanomaterial and to the electrostatic repulsion between the redox probe and the oxygenated groups of the nanomaterials. Certainly, while MWCNTs showed the highest Ret, $1811 \Omega$, GONR 55 and GCE showed lower values, 172.8 and $73.5 \Omega$, respectively. Furthermore, the highest resistance found for MWCNTs could be attributed to the lower conductivity of CNTs compared to hybrid nanomaterials [22]. It is reflected in a general electronic equivalent circuit (Randles and Ershler model), see Figure 3(C-D inset), which is very often used to model interfacial phenomena. It includes the ohmic resistance of the electrolyte solution, $\mathrm{R}_{\mathrm{s}}$, the Warburg impedance, $\mathrm{Z}_{\mathrm{W}}$, resulting from the diffusion of ions from the bulk electrolyte to the electrode interface, the double layer capacitance, $C_{d}$, and electron transfer resistance, $R_{c t}$, that exists if a redox probe is present in the electrolyte solution. 


$$
\mathrm{Fe}(\mathrm{CN})_{6}^{3-/ 4-}
$$

A

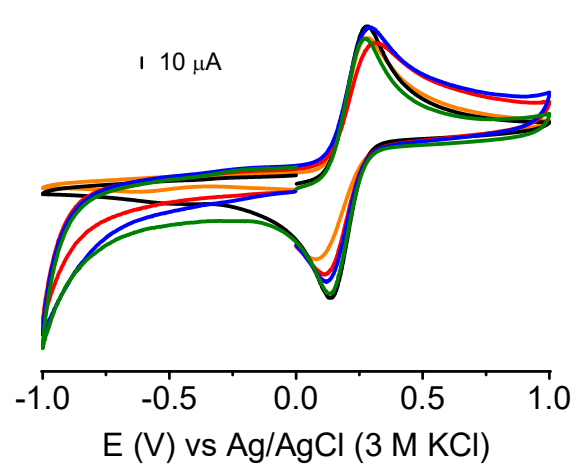

B
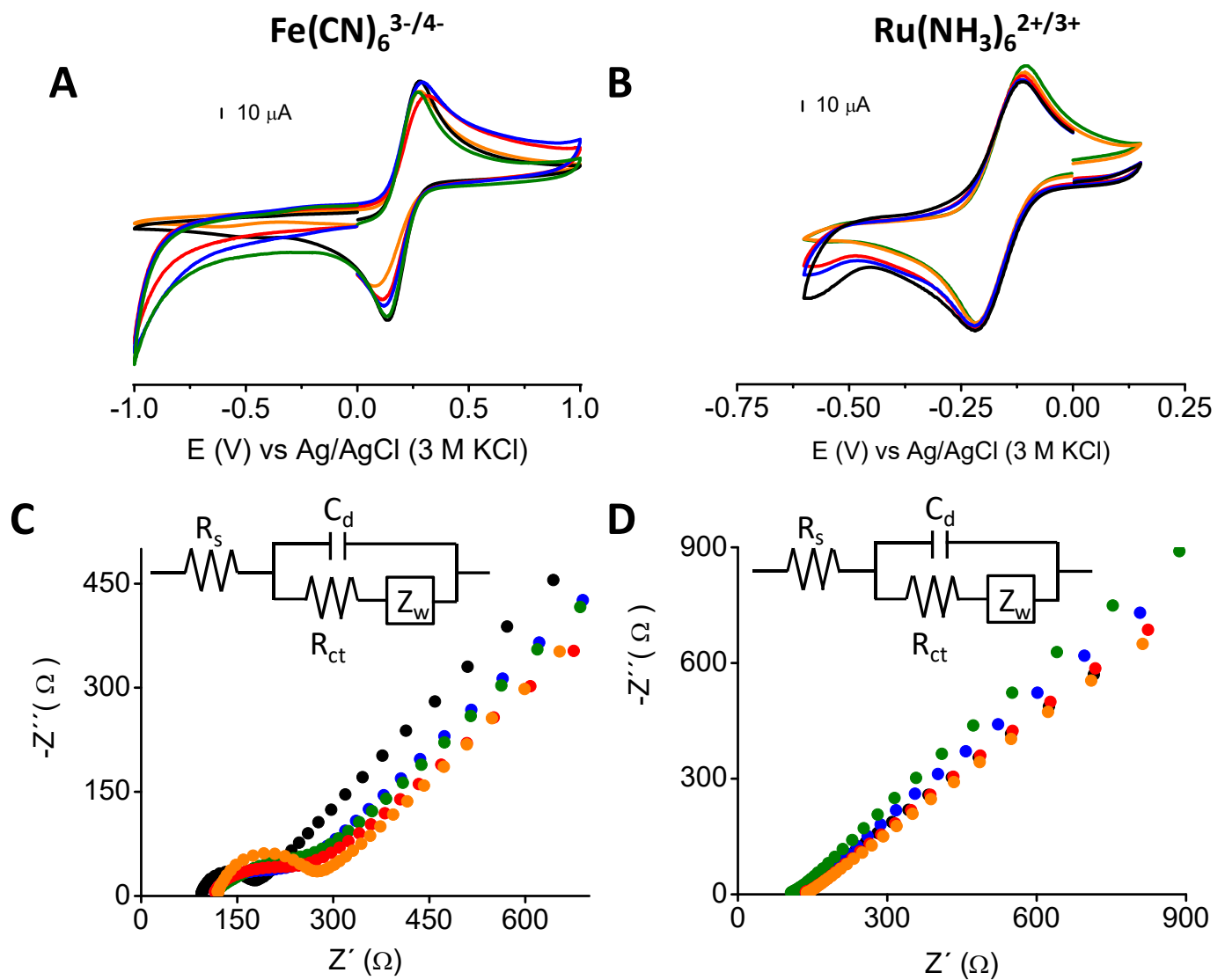

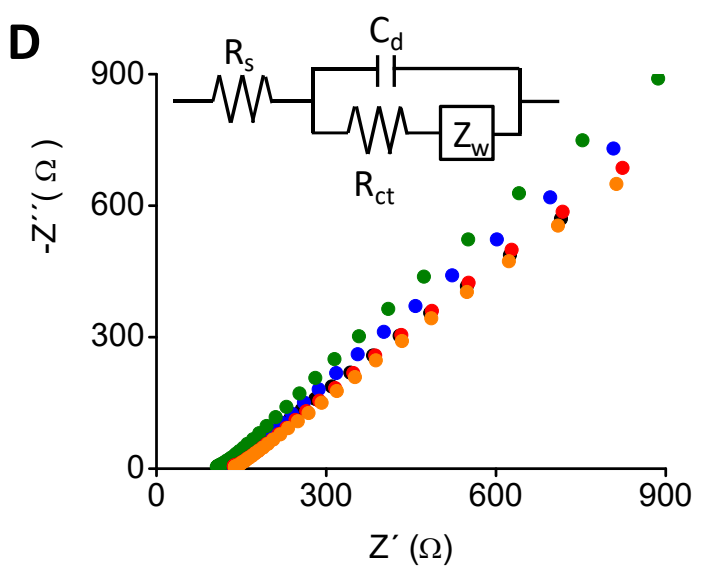

Figure 3. (A) CVs of $5 \mathrm{mM} \mathrm{Fe}(\mathrm{CN})_{6}{ }^{4-/ 3-}$ and (B) $5 \mathrm{mM} \mathrm{Ru}\left(\mathrm{NH}_{3}\right)_{6}{ }^{3+/ 2+}$ in $0.1 \mathrm{M} \mathrm{KCl}$. (C) Nyquist diagram of $5 \mathrm{mM} \mathrm{Fe}(\mathrm{CN})_{6}{ }^{4-/ 3-}$ and (D) $5 \mathrm{mM} \mathrm{Ru}\left(\mathrm{NH}_{3}\right)_{6}{ }^{3+/ 2+}$ in $0.1 \mathrm{M} \mathrm{KCl}$ (Inset: equivalent electrical circuit diagrams for impedance plots). GCE, MWCNTs, GONR55, GONR-65 and GONR-75.

The electrochemical sensing of GONRs was also assayed for a variety of model analytes (see Figure S) by. Prior to the analysis, the quantity of nanomaterial depesited on the GCE (Figure S6) and DPV conditions (Table S5) were optimized.

The rich chemistry obtained during the synthesis and preparation of carbon nanomaterials open novel avenues for a tailored nanomaterial for specific molecule detection. To this end, GONRs were assayed for the electrochemical sensing, by differential pulse voltammetry (DPV) because of its high selectivity and sensitivity, of target couples of analytes with significance in health (clinical and agro-food) sector, involving a wide variety of chemical structures with well-know electroactivity (see Figure 4). Prior to the analysis, the quantity of nanomaterial deposited on the GCE (Figure S5) and DPV conditions (Table S4) were optimized. 
More specifically, the detection of the couple catechol (CT) and resorcinol (RS) was chosen to evaluate the response in compounds with different chemical structures and same chemical formula (Figure 4). The simultaneous detection dopamine (DP) and uric acid (UA) as well as UA and tyrosine (Tyr) was carried out for their significant role as biomarkers in the monitoring of relevant diseases. Furthermore, simultaneous detection of hydroxytyrosol (HT) and tyrosol (TYL) is very important since they are quality markers in olive oil samples.

In all cases, GCE showed the lowest sensitivity and the highest oxidation potentials for the target molecules compared with the nanomaterial-modified GCE. Furthermore, the intensity currents increased on the GONRs and, in particular on GONR-65 surface as compared to MWCNTs, the initial carbon source (see Figure 4). For the detection of the couple catechol (CT) and resorcinol (RS) (Figure 4A), GONR 65 and GONR 75 showed the highest currents and, clearly the lowest potential for CT oxidation of +0.160 $\mathrm{V}$ as compared to GONR 55 material, MWCNT and bare GCE. The chemistry underlying the shifts in oxidation potentials in the electrochemical detection of the target molecules may be understood as follows. The oxidation of 1,2-benzenediol (CT) occurred at lower oxidation potentials whereas the oxidation of 1,3-diol (RS) is less favorable due to the lack of conjugation, thereby preventing the formation of the benzoquinone. We hypothesized that the availability of more $\pi-\pi$ interactions in GONRs facilitated the electrocatalysis of CT and RS in comparison with GCE and, therefore, facilitated oxidation of both benzenediols with the GONRs.

Simultaneous detection of dopamine (DP) and uric acid (UA) exhibited a much better performance on the GONR-65. GONR-65 exhibited an enhanced analytical sensitivity for UA 4-times and almost 2-times higher than the GCE and the hybrid counterparts, respectively (Figure 4B). DP, which basic structure derived from CT, displayed similar behavior for GONRs in comparison with GCE. Therefore, the predominant $\pi-\pi$ interactions plus hydrogen interactions between the benzenediol group and the GONRs surfaces appeared to be responsible for the similar responses.

Another couple of analytes, UA and tyrosine (Tyr), was studied, being only possible on the hybrid nanomaterial and not on the GCE the simultaneous resolution of both molecules. Furthermore, GONR65 showed the highest intensity currents 4-times higher than the GCE, 10-times higher than the MWCNT (initial carbon source) and 2-times 
higher than the GONR 55 and GONR 75 nanomaterials (Figure 4C). The oxidation process of L-Tyr was more difficult due to the presence of only one hydroxyl group. For this reason, the similar oxidation potentials observed on all carbon materials could be explained in terms of weak $\pi-\pi$ interactions between the tyrosine and the carbon materials.

In the detection of hydroxytyrosol (HT) and tyrosol (TYL), GONR-65 and GONR-55 exhibited the best electrochemical performance with well-defined oxidation peaks at lower potentials and enhanced oxidation currents (Figure 4D). It is worth to highlight the strong shift in the oxidation potential found for HT on these materials at $+0.129 \mathrm{~V}$ in comparison with those found in the others up to $+0.150 \mathrm{~V}$ and up to $+0.316 \mathrm{~V}$ for MWCNT and GCE. In this case, the oxidation of HT occurred at lower oxidation potentials whereas the oxidation of TYL was less favorable due to the lack of conjugation.

Overall, these results revealed that GONR-65 become the best material for all the studied analytes. This improved performance in terms of sensitivity (improved intensity currents) and selectivity (due to the shifts in oxidation potentials) of GONR 65, in most of the studied target health biomarkers, highlight the selectivity that some oxygenated functional groups have provided to this hybrid material. 
A<smiles>Oc1ccccc1O</smiles>

Catechol (CT)

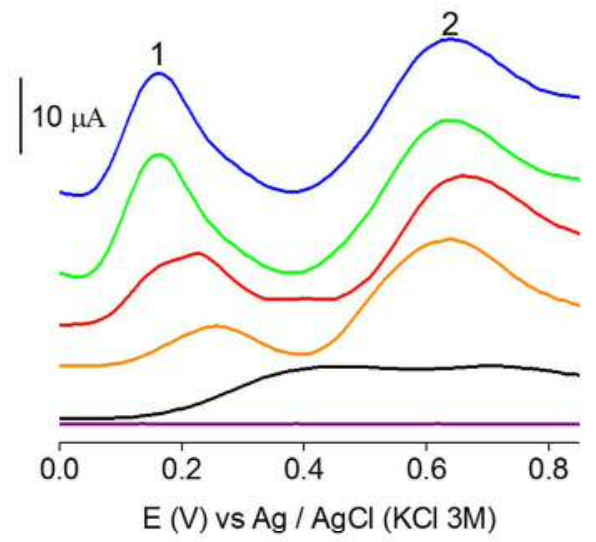

$\mathrm{C}$<smiles>N[C@@H](Cc1ccc(O)cc1)C(=O)O</smiles>

Uric Acid (UA)

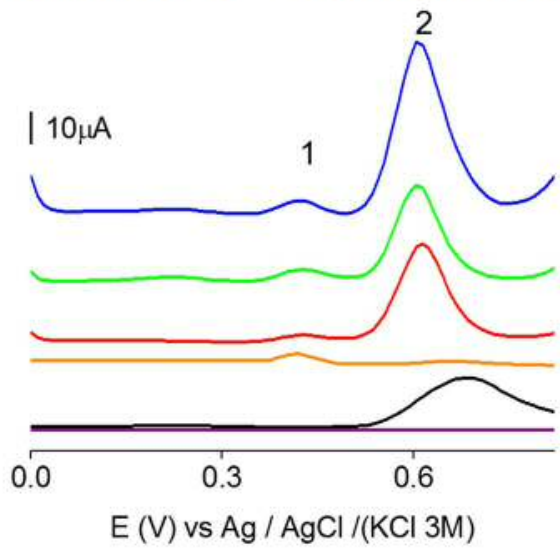

B<smiles>NCCc1ccc(O)c(O)c1</smiles>

Dopamine (DP)<smiles>O=c1[nH]c(=O)c2[nH]c(=O)[nH]c2[nH]1</smiles>

Uric Acid (UA)

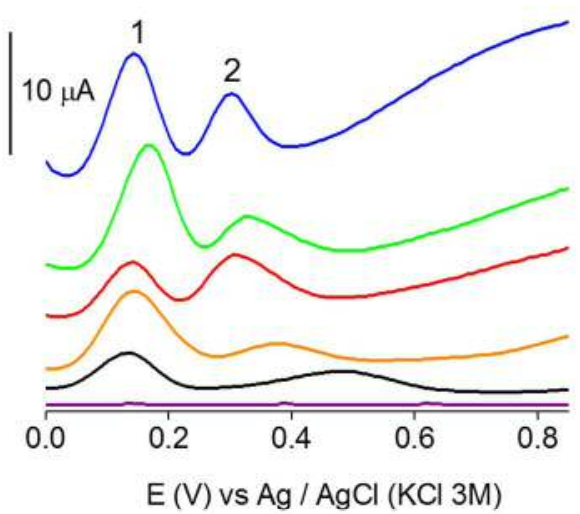

$D$ OHOH<smiles>OCCc1ccc(O)cc1</smiles>

Hydroxytyrosol (HT) Tyrosol (TYL)

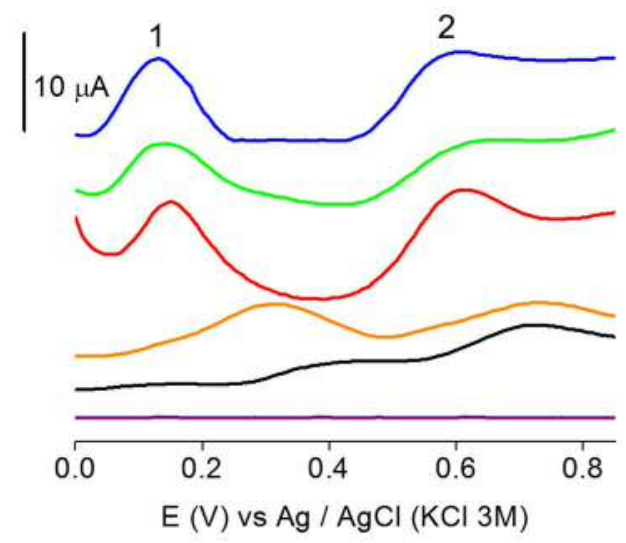

Figure 4. DPVs for the detection of: (A) CT $0.25 \mathrm{mM}$ (peak 1) and RS $1 \mathrm{mM}$ (peak 2), (B) DP $0.05 \mathrm{mM}$ (peak 1) and UA $0.1 \mathrm{mM}$ (peak 2), (C) UA $1 \mathrm{mM}$ (peak 1) and Tyr 1 $\mathrm{mM}$ (peak 2) and (D) HT $0.3 \mathrm{mM}$ (peak 1) and TYL $0.3 \mathrm{mM}$ (peak 2). Background signal (using the GCE), GCE, MWCNTs, GONR-55, GONR-65 and GONR-75 Experimental conditions: $0.01 \mathrm{M}$ PBS $(\mathrm{pH}=7.4)$, pulse amplitude $70 \mathrm{mV}$ and scan rate 5 $\mathrm{mVs}^{-1}$. (Structures of all the molecules under study).

GONR-65 also exhibited a very good performance in terms of precision with extremely low values of RSDs $\leq 1 \%$ for oxidation potentials and $\mathrm{RSDs} \leq 2 \%$ for intensity currents (see Table S3). Therefore, the studies revealed that GONR-65 contains controlled oxygen 
functionality with suitable electrochemical features for an improved analytical detection (revealed by DPV) of a variety of chemical structures.

In comparison with previous works using graphene nanoribbons, [18] the synthesized hybrid nanomaterial, GONR 65 performed in many cases lower oxidation potentials. As example, for CT the potential decreased to $+0.160 \mathrm{~V}$ in case of GONR 65 from the oxidation potential at $+0.243 \mathrm{~V}$ for the so called, oxidized graphene nanoribbons containing a $44 \%$ of oxygen content. Furthermore, in terms of sensitivity, molecules such as Tyr showed higher intensity currents 2-times higher than the so-called, reduced graphene nanoribbons (with a $14 \%$ of oxygen content) and 4-times higher than the oxidized graphene nanoribbons. In addition, the materials allowed the dopamine detection at lower oxidation potentials than in other works $[36,37]$ even in presence of uric acid and tyrosine.

\subsection{The chemistry behind the electrochemistry}

This general electrochemical behaviour of GONR-65 sample for the target molecules revealed by DPV seems to be associated to the balance between the $\mathrm{Csp}^{2} / \mathrm{Csp}^{3}$ ratio and the introduced functional groups. The edge-to-basal plane ratio [38] or the nanostructuration [39] are some of the reasons previously explored for graphene materials. In our case, at the light of the structural characterization, the oxygen functionalization seems to be also of chief importance.

As regard to the unzipping mechanism, potassium permanganate is an unusually selective oxidant for longitudinal cleavage of MWCNTs [26]. The first step is the formation of manganate ester as the rate-determining step. Pairs of oxygen atoms from the permanganate anion bind and break the internal $\mathrm{C}-\mathrm{C}$ bonds in the $\mathrm{CNT}$, the stretching of the bonds involved in the first attack weakens the neighbor parallel bonds making them more vulnerable for the next oxygen pair attack, which takes place longitudinally along the CNT [40]. After initial manganate ester formation, the vicinal diols that are formed will eventually cleave at the carbon-carbon bond between them giving dione and further oxidation of ketones to carboxylic acids takes place [17].

Temperature conditions seem to be critical for the GONRs formation and for the samples structure. Higginbotham et al. [26] have reported that exfoliated and highly oxidized GONRs are formed when temperature is maintained above $60^{\circ} \mathrm{C}$. From this reported data 
and our XPS results, it seems feasible that $55^{\circ} \mathrm{C}$ is not enough temperature for the fast progress of the unzipping reaction. $65^{\circ} \mathrm{C}$ is, under the conditions used, the optimum temperature to promote the MWCNTs unzipping and to avoid the excessive oxidation to diones of the vicinal diols formed in the basal plane of graphene during oxidation. As it can be seen from Table 2 (XPS), GNR65 sample shows the highest contribution at 286.7 $\mathrm{eV}(\mathrm{C} 1 \mathrm{~s})$ and at $532.3 \mathrm{eV}(\mathrm{O} 1 \mathrm{~s})$ that seems to make GNR65 the most electrochemically active material.

The unzipping process involves the decrease of $\mathrm{Csp}^{2}$ due to the anchoring of oxygen functional groups in the conductive network of graphene backbone that disrupt the $\mathrm{sp}^{2}$ structure. In addition to the reduction of $\mathrm{Csp}^{2} / \mathrm{Csp}^{3}$, the graphitic fraction as calculated from XRD, the type of functional groups introduced and possibly their position influence the sensitivity and the selectivity in the electrochemical performance as revealed by DPV.

The highest selectivity could be ascribed not only to the type of functional groups but to their position. Certainly, under Lerf-Klinowski model, for graphene oxides, hydroxyl and ethers are mainly located in the inner part of the graphene layers while $\mathrm{COOH}$ and $\mathrm{C}=\mathrm{O}$ are distributed along the boundaries [28]. The presence of hydroxyl (aliphatic and aromatic in higher amount in GONR65 seemed to be the main chemical difference in the structure. A further oxidation in GONR-75, led to overoxidation to diones with subsequent hole generation and higher oxygen content, but diffusion and migration limitations due to the loss of $\mathrm{sp}^{2}$ domains connectivity that leads to worse electrochemical performance.

\section{Conclusion}

The controlled-chemical oxidation of MWCNTs generating GONRs opens new gates in the edge chemistry of carbon nanomaterials to be exploited as novel materials for electrochemical sensing and biosensing of target relevant molecules. GONR-65 became an interesting material, containing specific oxygen moieties with suitable electrochemical features, and exhibited the best analytical performance in the electrochemical sensing of molecules with different chemical structure. These combined features yielded excellent electrocatalytic properties due to the effects of both the $\pi-\pi$ and hydrogen bonds interactions between the molecules and the GONR-65. 
These carbon nanomaterials open new opportunities for electrochemical sensing applications and guide the process to the production of advanced materials to be used in an specific molecular detection application.

\section{Acknowledgements}

This work has been Financial supported by the Spanish Ministry of Science and Innovation (CTQ2011-28135), the NANOAVANSENS program from the Community of Madrid (S2013/MIT-3029), the Spanish MINECO (ENE2013-48816-C5-5-R), the Government Aragon (Project DGA_ESF-T66 CNN) and the European Social Fund (ESF). D. A. M. acknowledges the FPU fellowship from the Ministry of Education, Culture and Sports. D. M. M.-G. acknowledges the fellowship received from the NANOAVANSENS program.

\section{References}

[1] Y. Jang, C. Han, B. Jiang, J. Iocozzia, C. He, D. Shi, T. Jiang, Z. Lin. Materials Science \& Engineering R-Reports. 102 (2016) 1-72

[2] B. H. Nguyen, V. H. Nguyen. Advances in Natural Sciences-Nanoscience and Nanotechnology, 7 (2016) 023002-023

[3] Y. Liu, F. Wang, Y. Liu, X. Wang, Y. Xu, R. Zhang. Nanoscale, 8 (2016) 1288312886.

[4] D. R.K. Joshi, S. Alwarappan, M. Yoshimura, V. Sahajwalla, Y. Nishina, Appl. Mater. Today 1 (2015) 74-79.

[5] R.L. McCreery, Advanced Carbon Electrode Materials for Molecular Electrochemistry, Chem. Rev. 108 (2008) 2646-2687.

[6] D. Chen, H. Feng, J. Li, Graphene Oxide: Preparation, Functionalization, and Electrochemical Applications, Chem. Rev. 112 (2012) 6027-6053.

[7] A. G. Crevillen, M. Pumera, M. C. Gonzalez A. Escarpa, The preferential electrocatalytic behaviour of graphite and multiwalled carbon nanotubes on enediol groups and therir analytical implications in real domains, Analyst 134 (2009) 657-662. 
[8] A. Martín, A. Escarpa, The cutting-edge interaction between chemistry and electrochemistry, Trend. Anal. Chem. 56 (2014) 13-26.

[9] S. Iijima, Helical microtubules of graphitic carbon, Nature 354 (1991) 56-58.

[10] S. Iijima, T. Ichihashi, Single-shell carbon nanotubes of $1 \mathrm{~nm}$ diameter, Nature 363 (1993) 603-605.

[11] S. Stankovich, D.A. Dikin, G.H.B. Dommett, K.M. Kohlhaas, E.J. Zimney, E.A. Stach, et al., Graphene-based composite materials, Nature 442 (2006) 282-286.

[12] M. Pumera, A. Ambrosi, A. Bonanni, E.L.K. Chng, H.L. Poh, Graphene for electrochemical sensing and biosensing, Trend. Anal. Chem. 29 (2010) 954-965.

[13] A. H. C. Neto, F. Guinea, N.M.R. Peres, K.S. Novoselov, A.K. Geim., The electronic properties of graphene, Rev. Mod. Phys. 81 (2009) 109-162

[14] D. AC. Brownson, D.K. Kampouris, C.E. Banks. Graphene electrochemistry: fundamental concepts through to prominent applications. Chemical Society Reviews, 41 (2012) 6944-6976

[15] A. Ambrosi, C. K. Chua, A. Bonanni, M. Pumera. Electrochemistry of graphene and related materials. Chem. Rev. 114 (2014) 7150-7188

[16] M. Pumera. Electrochemistry of graphene, graphene oxide and other graphenids: Review. Electrochem. Commun. 36 (2013) 14-18.

[17] D.V. Kosynkin, A.L. Higginbotham, A. Sinitskii, J.R. Lomeda, A. Dimiev, B.K. Price, et al., Longitudinal unzipping of carbon nanotubes to form graphene nanotibbons, Nature 458 (2009) 872-876.

[18] A.G. Cano-Marquez, F.J. Rodriguez-Macias, J. Campos-Delgado, C.G. EspinosaGonzalez, F. Tristan-Lopez, D. Ramirez-Gonzalez, et al., ExMWNTs: Graphene Sheets and Ribbons Produced by Lithium Intercalation and Exfoliaiton of Carbon nanotubes, Nano Lett. 9 (2009) 1527-1533.

[19] A. Martín, J. Hernández, L. Vázquez, M.T. Martínez, A. Escarpa, Controlled chemistry of tailored graphene nanoribbons for electrochemistry: a rational approach to optimizing molecule detection, RSC Adv. 4 (2014) 132-139. 
[20] A. Martín, J. Hernández-Ferrer, M. T. Martínez, A. Escarpa, Graphene nanoribbonbased electrochemical sensor son screen-printed platforms, Electrochim. Acta 172 (2015) 2-6.

[21] J. Hernández-Ferrer, P. Laporta, F. Gutiérrez, M. D. Rubianes, G. Rivas, M. T. Martínez, Multi-walled carbon nanotubes/graphene nanoribbons hybrid materials with superior electrochemical performance, Electrochem. Comm. 39 (2014) 26-29.

[22] C.L. Sun, C.T. Chang, H.H. Lee, J. Zhou, J. Wang, T.K. Sham, W.F. Pong, ACS Nano, 5 (2011) 7788-7795.

[23] G. Zhu, Y.Yi, B. Zou, Z. Liu, J. Sun, X. Wu, Microchimica Acta, 182, (2015) 871877.

[24] G. Zhu, Y. Yi, Z. Han, K. Wang, X. Wu, Anal. Chim. Acta, 845 (2014) 30-37.

[25] Y. Liu, Y. Liu, H. Feng, Y. Wu, L. Joshi, X. Zeng, J. Li Layer-by-layer assembly of chemical reduced graphene and carbon nanotubes for sensitive electrochemical immunoassay Biosensors Bioelectronics, 35 (2012) 63-68.

[26] A.L. Higginbotham, D.V. Kosynkin, A. Sinitskii, Z. Sun, J.M. Tour, Lower-Defect graphene oxide nanoribbons from multiwalled carbon nanotubes, ACS Nano 4 (2010) 2059-2069.

[27] J.M. Honig, L.H. Reyerson, Adsorption of nitrogen, oxygen, and argon on rutile at low temperature: applicability of the concept of surface heterogeneity, J. Phys. Chem. $1952,56,140-146$.

[28] S. Niyogi, E. Bekyarova, M. E. Itkis, H. Zhang, K. Shepperd, J. Hicks, et al., Spectroscopy of covalently functionalized graphene, Nano Lett 10 (2010) 4061-4066.

[29] A. Eckmann, A. Felten, A. Mishchenko, L. Britnell, R. Krupke, K. S. Novoselov, et al., Probing the nature of defects in graphene by Raman Spectroscopy, Nano Lett. 12 (2012) 3925-3930.

[30] J.L. Figueiredo, M.F.R. Pereira, M.M.A. Freitas, J.J.M. Órfao, Carbon, 37 (1999) 1379-1389. 
[31] J. L. Figueiredo, M. F. R. Pereira, Modification of the Surface chemistry of activated carbons, Catal. Today 150 (2010) 2-7.

[32] J. Coates. Encyclopedia of Analytical Chemistry; Meyers, R. A. Ed. John Wiley \& Sons Ltd, Chichester, (2000), 10815.

[33] D.J. Miller, M.C. Biesinger, N.S. McIntyre, Interactions of $\mathrm{CO}_{2}$ and $\mathrm{CO}$ at fractional atmosphere pressures with iron and iron oxide surfaces: one possible mechanism for surface contamination? Surf Interface Anal 33 (2002) 299-305.

[34] C. H.A. Wong, M. Pumera. Phys. Chem. Chem. Phys. 15 (2013), 7755-7759.

[35] D. A.C. Brownson, A. C. Lacombe, M. Gómez-Mingot, C. E. Banks. Graphene oxide gives rise to unique and intriguing voltammetry. RSC Adv. 2 (2012) 665-668.

[36] B. L. Tang, Y. Wang, Y. Li, H. Feng, J. Lu, J. Li, Preparation, Structure, and Electrochemical Properties of Reduced Graphene Sheet Films, Adv. Funct. Mater. 19 (2009) 2782-2789.

[37] Y. Wang, Y. Li, L. Tang, J. Lu, J. Li, Application of graphene-modified electrode for selective detection of dopamine, Electrochem. Commun. 11 ( 2009) 889-892.

[38] D.A.C. Brownson, L.J. Munro, D.K. Kampouris, C.E. Banks, Electrochemistry of graphene: not such a beneficial electrode material? RSC Adv. 1 (2011) 978-988.

[39] S. Chen, Y. Liu, J. Chen, Heterogeneous electron transfer at nanoscopic electrodes: importance of electronic structures and electric double layers, Chem Soc. Rev. 43 (2014) $5372-5386$

[40] N.L. Rangel, J.C. Sotelo, J. M. Seminario. Mechanism of Carbon Nanotubes Unzipping into Graphene Ribbons, J. Chem. Phys.131 (2009) 031105. 


\section{Electronic Supplementary Information}

\section{Electrochemical behavior of glassy carbon electrode modified with different hybrid carbon nanomaterials}

María del Carmen Marín ${ }^{1}$, Aída Martín ${ }^{1}$, María Moreno-Guzman ${ }^{1}$, Alejandro Ansón-Casaos ${ }^{2}$, María Teresa Martínez ${ }^{2^{*}}$ and Alberto Escarpa ${ }^{1^{*}}$

${ }^{1}$ Department of Analytical Chemistry, Physical Chemistry and Chemical Engineering University of Alcalá, E-28871. Alcalá de Henares, Madrid, Spain.

${ }^{2}$ Instituto de Carboquímica ICB-CSIC, Miguel Luesma Castán, 4, 50018 Zaragoza, Spain

*To whom the correspondence should be applied.

E-mail: alberto.escarpa@uah.es,mtmartinez@icb.csic.es.

FAX number: (+34) 918854971 


\section{Table of contents}

1. Thermogravimetric analysis for MWCNTs and GNR materials

2. Structural characterization

2.1. Infrared spectroscopy

2.2. X-ray photoelectron spectroscopy

3. Electrochemical characterization 


\section{Thermogravimetric analysis for MWCNTs and GNR materials}

Thermogravimetric analyses (TGA) were performed to confirm the oxidation of the GONRs while increasing the temperature from 55 to $75^{\circ} \mathrm{C}$. MWCNTs confirmed the low content of functional groups.

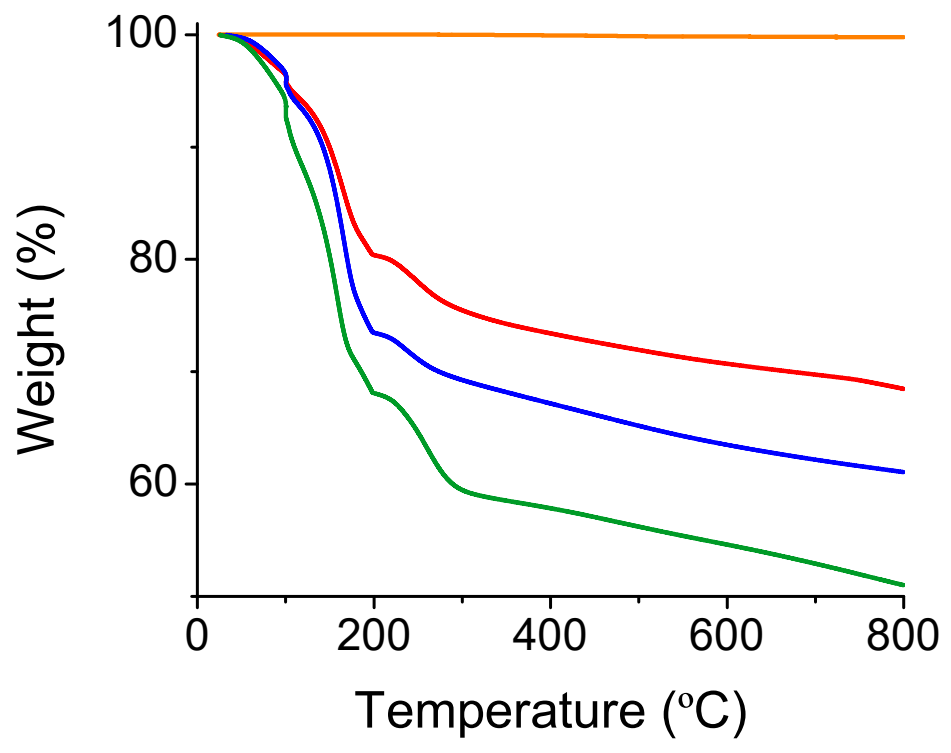

Figure S1. Thermogravimetric analysis (TGA) thermograms of MWCNTs, GONR-55, GONR65 and GONR-75 materials. 


\section{Structural characterization}

\subsection{IR spectroscopy}

To gain further insight into the oxygenated functional groups introduced in the oxidative treatment IR-FTIR characterization was carried out (see Figure S2 and Table S1)

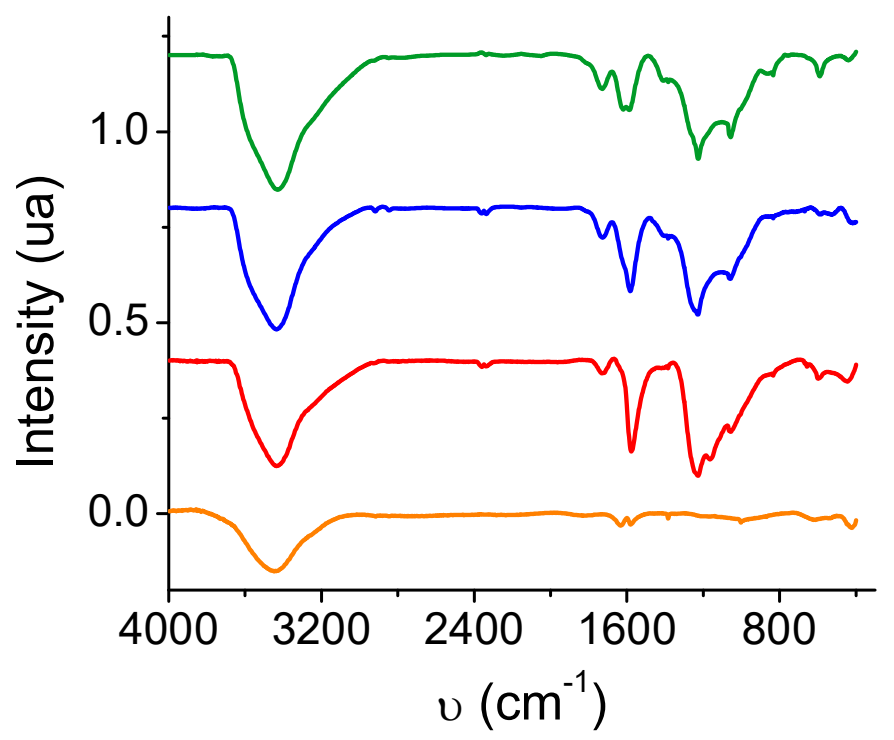

Figure S2. IR-FTIR spectra of MWCNTs, GONR-55, GONR-65 and GONR-75 samples

Table S1. Main FTIR bands $\left(v, \mathrm{~cm}^{-1}\right)$ of MWCNTs and GONRs samples

\begin{tabular}{ccccc}
\hline Functional Group & MWCNTs & GONR-55 & GONR-65 & GONR-75 \\
\hline Hydroxyl groups & 3437 & 3439 & 3430 & 3429 \\
\hline Carboxyl groups & - & 1732 & 1732 & 1730 \\
\hline Adsorbed $\mathrm{H}_{2} \mathrm{O}$ & 1634 & - & 1620 & 1620 \\
\hline Carboxylates & 1581 & 1576 & 1587 & 1585 \\
\hline $\begin{array}{c}\text { OH bend phenols or } \\
\text { tertiary alcohols }\end{array}$ & 1384 & 1385 & 1387 & 1385 \\
\hline C-O stretch phenols & --- & 1229 & 1228 & 1227 \\
\hline $\begin{array}{c}\text { C-O stretch, } \\
\text { secondary alcohols }\end{array}$ & --- & 1165 & --- & -- \\
\hline $\begin{array}{c}\text { C-O stretch, } \\
\text { primary alcohols }\end{array}$ & 1045 & 1070 & 1057 & 1057 \\
\hline $\begin{array}{c}\text { Aromatic C-H out- } \\
\text { of-plane bend }\end{array}$ & --- & 833 & 833 & 833 \\
\hline
\end{tabular}




\subsection{X-ray photoelectron spectroscopy}
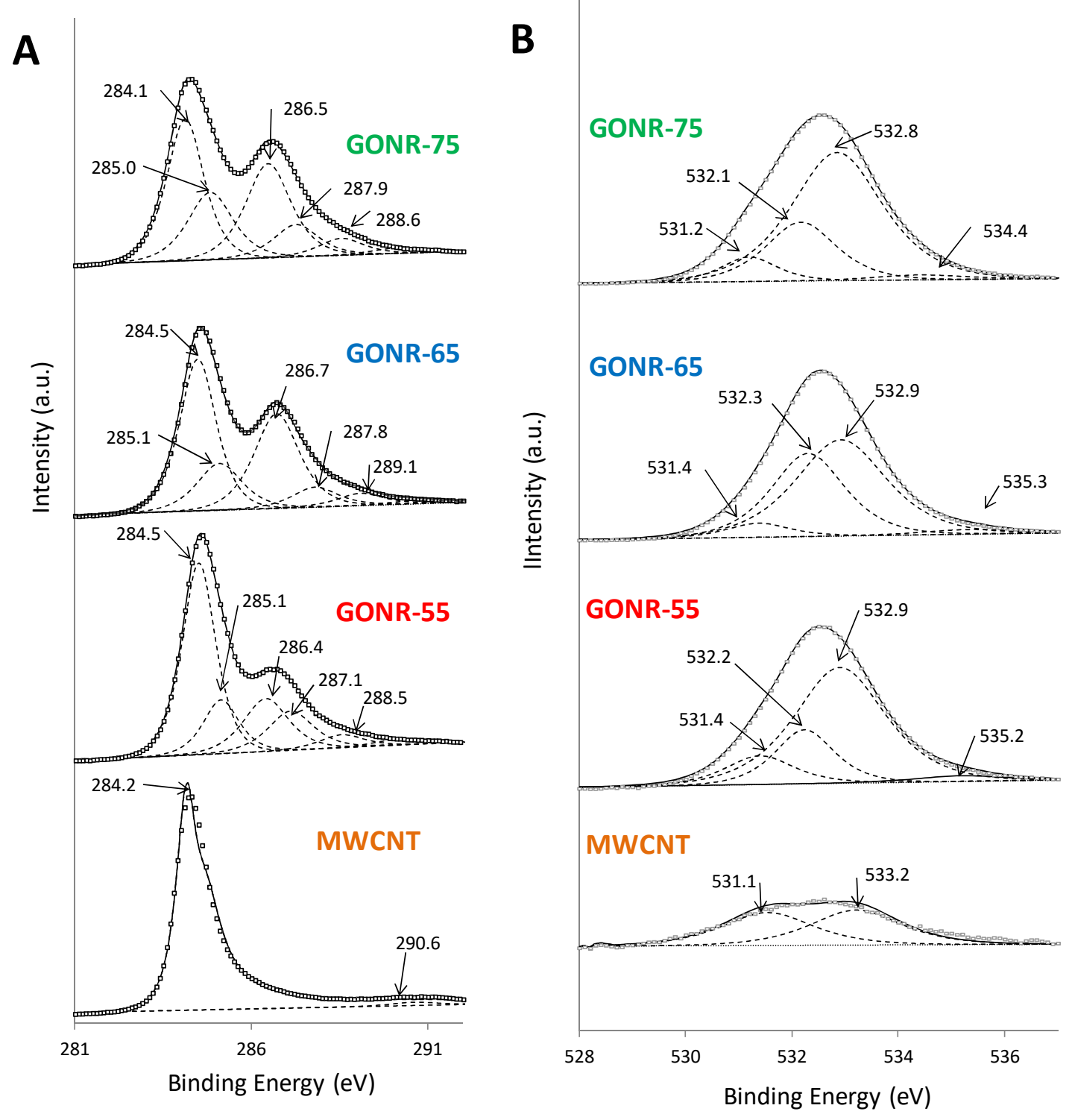

Figure S3. Deconvoluted (A) C1s and (B) O1s XPS spectra of MWCNTs, GONR-55, GONR-65 and GONR-75 materials. Areas of the corresponding sub-bands in Table S2 


\section{Electrochemical characterization}

The electrode surface was characterized by cyclic voltammetry.

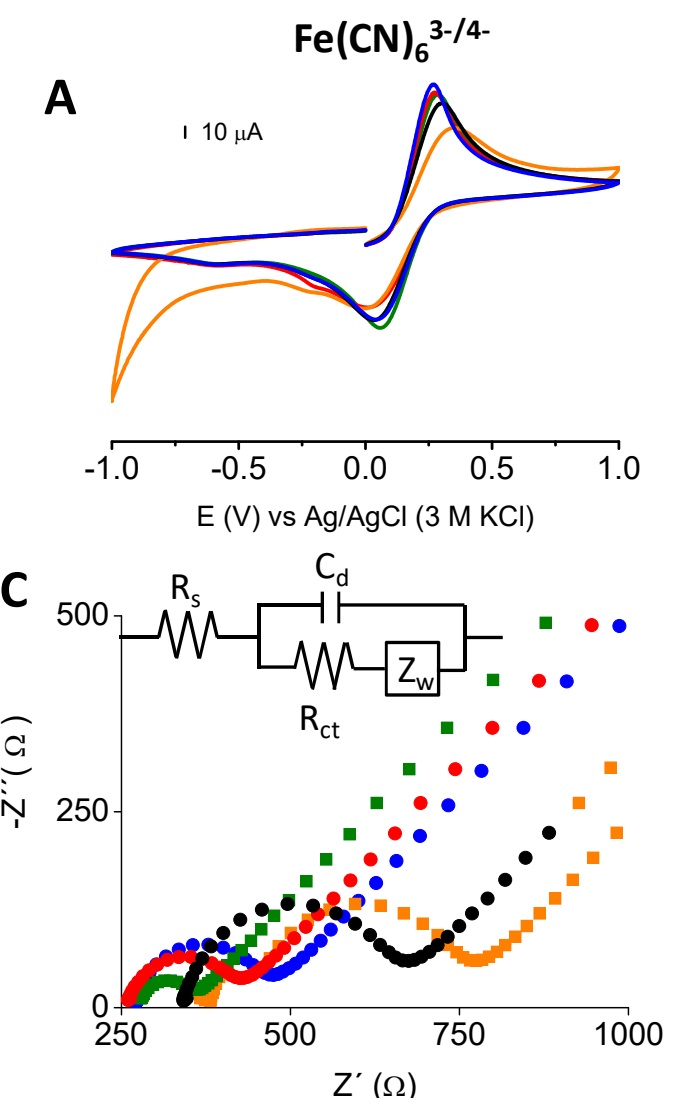

B
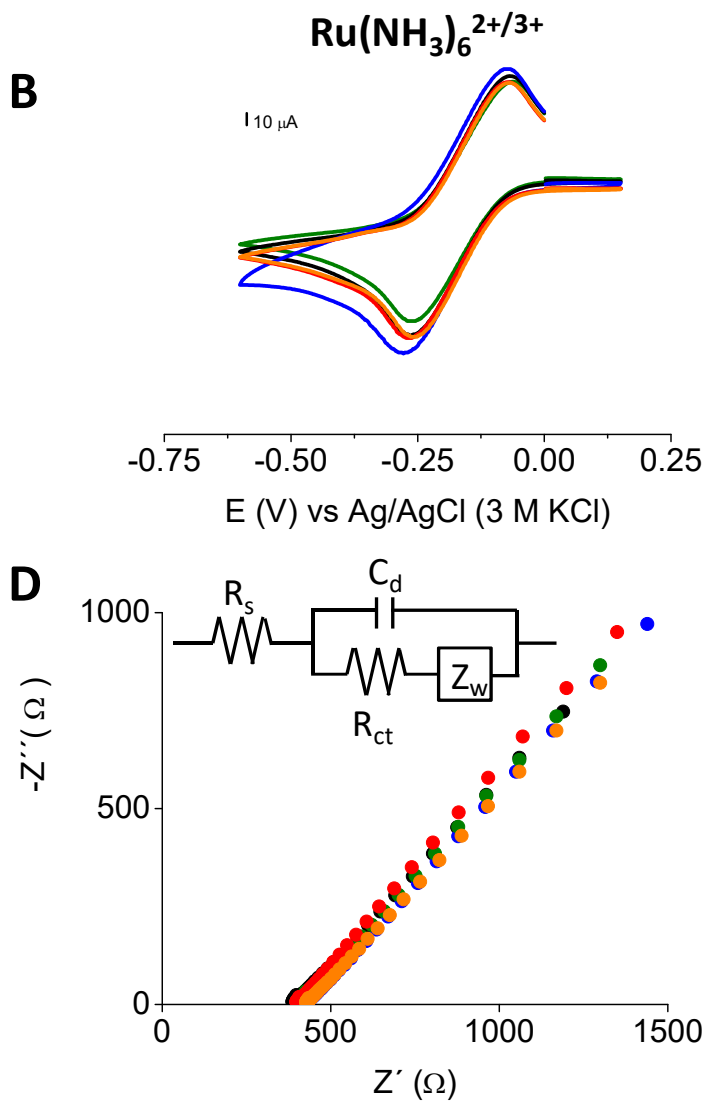

Figure S4. (A) $\mathrm{CVs}$ of $5 \mathrm{mM} \mathrm{Fe}(\mathrm{CN})_{6}{ }^{4-/ 3-}$ and (B) $5 \mathrm{mM} \mathrm{Ru}\left(\mathrm{NH}_{3}\right)_{6}{ }^{3+/ 2+}$ in $10 \mathrm{mM}$ phosphate buffer. (C) Nyquist diagram of $5 \mathrm{mM} \mathrm{Fe}(\mathrm{CN})_{6}{ }^{4-/ 3-}$ and (D) $5 \mathrm{mM} \mathrm{Ru}\left(\mathrm{NH}_{3}\right)_{6}$ ${ }^{3+/ 2+}$ in $10 \mathrm{mM}$ phosphate buffer (Inset: equivalent electrical circuit diagrams for impedance plots). GCE, MWCNTs, GONR-55, GONR-65 and GONR-75.

Table S2. Charge transfer resistance $\left(\mathrm{R}_{\mathrm{ct}}\right)$ in MWCNTs and GONRs samples and versus the $\operatorname{GCE}\left(\Delta \mathrm{R}_{\mathrm{ct}}\right)$ for of $5 \mathrm{mM} \mathrm{Fe}(\mathrm{CN})_{6}{ }^{4-3}$-in $0.01 \mathrm{M} \mathrm{PBS}$ and in $0.1 \mathrm{M} \mathrm{KCl}$.

\begin{tabular}{ccc|cc}
\hline Material & $\mathbf{R}_{\text {ct }}(\boldsymbol{\Omega})$ inPBS & $\Delta \mathbf{R}_{\text {ct }}(\boldsymbol{\Omega})$ in PBS & $\mathbf{R}_{\text {ct }}(\Omega)$ in $\mathbf{K C l}$ & $\begin{array}{c}\Delta \mathbf{R}_{\text {ct }}(\Omega) \text { in } \\
\text { KCl }\end{array}$ \\
\hline GCE & 73.5 & --- & 112.6 & -- \\
\hline MWCNT & 1811.0 & 1737.5 & 150 & 37.4 \\
\hline GONR-55s & 172.8 & 99.3 & 84.4 & -28.2 \\
\hline GONR-65 & 794.1 & 720.7 & 80.0 & -32.6 \\
\hline
\end{tabular}




\begin{tabular}{lcc|cc}
\hline GONR-75 & 524.9 & 451.5 & 101.3 & 11.3 \\
\hline
\end{tabular}

Study of volume optimization using DPV.

A

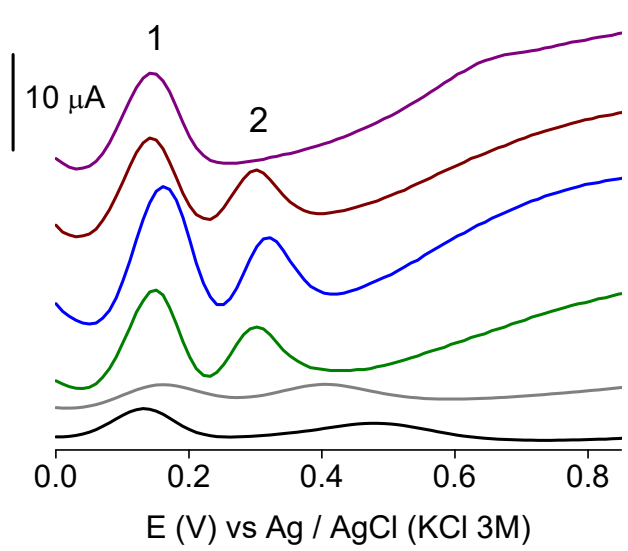

B

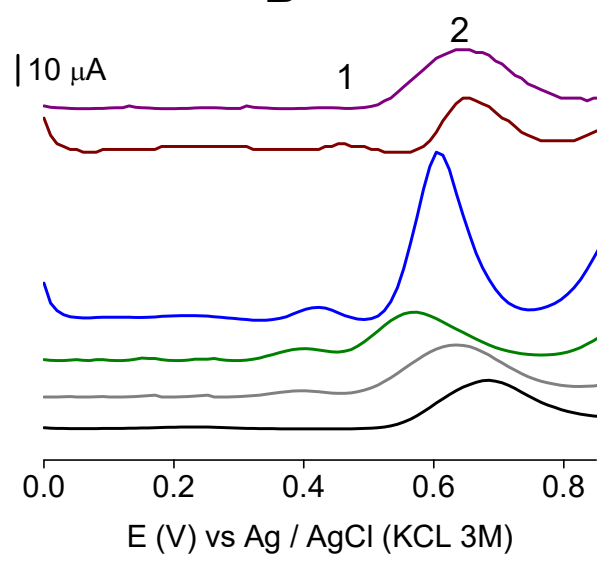

Figure S5. DPVs for the detection of: (A) DP $0.05 \mathrm{mM}$ (peak 1) and UA $0.1 \mathrm{mM}$ (peak 2), (B) UA $1 \mathrm{mM}$ (peak 1) and Tyr $1 \mathrm{mM}$ (peak 2). GCE (in black) and different casting volumes of GONR-65 $0.8 \mu \mathrm{L}$ (grey), 3.0 $\mu \mathrm{L}$ (green), 5.0 $\mu \mathrm{L}$ (blue), 7.0 $\mu \mathrm{L}$ (red), 10.0 $\mu \mathrm{L}$ (purple). 
Repeatability studies of selected molecules using DPV are listed in Table S3.

Table S3. Relative standard deviations (RSDs, \%) obtained for two selected molecules DP and HT on the GCE, MWCNTs and GONR-65 in terms of current and potentials.

\begin{tabular}{ccccccc}
\hline & \multicolumn{6}{c}{ Repeatability, RSD (\%) (n=10) } \\
\cline { 2 - 7 } Analytes & \multicolumn{2}{c}{ GCE } & \multicolumn{2}{c}{ MWCNTs } & \multicolumn{2}{c}{ GONR-65 } \\
\cline { 2 - 7 } & Current & Potential & Current & Potential & Current & Potential \\
\hline DP & 7.1 & 2.0 & 3.1 & 3.1 & 2.0 & 0.9 \\
\hline HT & 3.3 & 2.1 & 1.9 & 1.2 & 1.0 & 0.6 \\
\hline
\end{tabular}

Optimization of DPV features is detailed in Table S4.

Table S4. Study of pulse amplitude in the DPV, percentage shift versus $70 \mathrm{mV}$ pulse amplitude for uric acid (UA) and tyrosine (Tyr) detection.

\begin{tabular}{ccc}
\hline Pulse amplitude, $\mathrm{mV}$ & $(\%) \mathrm{I} / \mathrm{I} 70 \mathrm{mV}(\mathrm{UA})$ & $(\%) \mathrm{I} / \mathrm{I} 70 \mathrm{mV}(\mathrm{Tyr})$ \\
\hline 100 & 100 & 100 \\
70 & 100 & 100 \\
50 & 60 & 50 \\
20 & 24 & 19 \\
10 & 11 & 7 \\
5 & 4 & 3 \\
\hline
\end{tabular}

Both modulation time in the range from $5 \mathrm{~ms}$ and $100 \mathrm{~ms}$ and pulse amplitude in the range from 5 to $70 \mathrm{mV}$ were studied. When the pulse amplitude was increased, the sensitivity was enhanced reaching a constant value after $70 \mathrm{mV}$. However, the modulation time did not show differences at that optimized pulse amplitude value. 